\title{
Mapeamento da vulnerabilidade geoambiental do estado do Paraná
}

\section{Leonardo José Cordeiro Santos ${ }^{1}$, Chisato Oka-Fiori', Naldy Emerson Canalli', Alberto Pio Fiori ${ }^{2}$, Claudinei Taborda da Silveira ${ }^{3}$ \& Julio Manoel França da Silva ${ }^{3}$}

\begin{abstract}
Resumo O mapeamento da vulnerabilidade geoambiental do estado do Paraná, elaborado na escala 1:600.000, fundamenta-se no método da Análise Empírica da Fragilidade dos Ambientes Naturais e Antropizados apresentado por Ross (1994). Para obtenção das classes de vulnerabilidade foram levadas em conta a geologia, a geomorfologia e a pedologia, considerando-se três classes: baixa, moderada e alta, aplicadas em cinqüenta unidades geomorfológicas definidas no Paraná por Oka-Fiori et al. (2006) e Santos et al. (2006). As classes de vulnerabilidade estão condicionadas aos processos geoambientais: erosão, movimentos de massa, queda de blocos, subsidência, recalques e colapsos de solo, inundações periódicas e contaminação de águas subterrâneas. Foram identificados os problemas esperados e a aptidão de uso para cada unidade. A integração entre as informações espaciais foi realizada com o uso de geoprocessamento, aplicando combinações numéricas e operadores de soma ponderada em matrizes, no software Arcview 3.2, Spatial Analyst e 3D Analyst (ESRI, 1996). O resultado do trabalho visa atender a demanda por uma base sistemática para o planejamento ambiental do estado do Paraná.
\end{abstract}

Palavras-Chave: vulnerabilidade geoambiental, estado do Paraná, processos geoambientais, planejamento

\begin{abstract}
Mapping of geo-environmental vulnerability of the Paraná state. The geo-environmental vulnerability mapping of Paraná State, elaborated at the 1:600.000 scale, was based on the "Análise Empírica da Fragilidade dos Ambientes Naturais e Antropizados" method presented by Ross (1994). For attainment of the vulnerability classes, geology, geomorphology and pedology were considered in three classes, low, moderate and high, applied on fifty geomorphologic units defined in Paraná state by Oka-Fiori et al. (2006) and Santos et al. (2006). The vulnerability classes are characterized by a variety of geo-environmental processes: erosion, movements of mass, fall of blocks, soil subsidence, ground collapses, periodic flooding and underground water contamination. The expected problems and the aptitude of use for each unit were identified. The integration between the various spatial informations was carried out trough geo-processing techniques, having applied numerical combinations and operators of weighed addition in matrices and using Arcview 3,2, Spatial Analyst and 3D Analyst softwares. The result of the work aims at to take care of the demand for a systematic base to environmental action planning in Paraná state.
\end{abstract}

Keywords: geo-environmental vulnerability, Paraná State, geo-environmental processes, planning

INTRODUÇÃOO A eficiência da gestão ambiental de um território depende em grande parte de levantamentos e estudos sistemáticos prévios sobre os principais elementos e condicionantes do meio físico. A ocupação inadequada do espaço e a utilização indevida dos recursos naturais podem acarretar sérios problemas ambientais.

Atualmente há um crescente número de trabalhos que buscam oferecer novas soluções metodológicas em relação ao planejamento e gestão ambiental no sentido de compreender e mitigar as influências antrópicas sobre os processos naturais. Estas novas metodologias, em sua maioria, utilizam o geoprocessamento, cuja aplicação é um valioso recurso de apoio possibilitando avaliar o potencial dos recursos naturais - físiconaturais e bióticos - da paisagem mediante a análise integrada de seus componentes. Estas técnicas viabili- zam a gestão e simulações de cenários futuros, dentre inúmeras outras aplicabilidades.

De maneira geral, verifica-se na literatura nacional e internacional a existência de diversas metodologias de estudo do meio físico aplicadas na análise ambiental e/ou planejamento territorial. Pires Neto (1995), ao analisar algumas dessas metodologias de estudo do meio físico, agrupou-as em dois principais conjuntos distintos: o primeiro vinculado a estudos de cartografia geotécnica, utilizados principalmente em escala de detalhe, para subsidiar as atividades de engenharia, planejamento, construção e exploração mineral; o segundo conjunto de abordagem, adotado normalmente para mapeamentos em escalas de 1:100.000 ou menores, que funciona como uma orientação geral para o planejamento, tendo como finalidade a identificação e a delimitação de áreas funcionais com base nas suas

1 - Depart. Geografia, Univ. Federal do Paraná, Curitiba (Pr), Brasil. E-mails: santos@ufpr.br; chisato@ufpr.br; naldy@brturbo.com.br

2 - Departamento de Geologia, Universidade Federal do Paraná, Curitiba (Pr), Brasil. E-mail: fiori@ufpr.br

3 - Programa de Pós-Graduação, Depart. Geografia, Univ. Federal Paraná, E-mails: claudineits@pop.com.br; juliogeog@yahoo.com.br 
potencialidades e vulnerabilidades.

No presente trabalho adotou-se a segunda forma de abordagem mencionada, tendo em vista maior compatibilidade com a dimensão da área estudada - o estado do Paraná.

O território paranaense localiza-se na porção Meridional do Brasil e tem como limites ao norte o estado de São Paulo, a leste o oceano Atlântico, ao sul o estado de Santa Catarina, a sudoeste e oeste sucessivamente as Repúblicas da Argentina e do Paraguai e, a noroeste, o estado do Mato Grosso do Sul. Ocupa uma área de $199.575 \mathrm{~km}^{2}$, caracterizada por um relevo predominantemente planáltico.

Este trabalho vem complementar estudos anteriores desenvolvidos pelo grupo de pesquisa e publicados em Oka-Fiori et al. (2006) e Santos et al. (2006), decorrentes do Mapeamento Geomorfológico do Estado do Paraná. O presente trata do mapeamento da vulnerabilidade geoambiental do estado do Paraná, na escala 1:600.000 e constitui-se num documento básico para os estudos ambientais e de gestão territorial no estado do Paraná, visto que apresenta uma visão sistemática das grandes áreas com potencial de uso e as áreas vulneráveis à degradação ambiental.

O Mapeamento Geomorfológico do Paraná definiu as unidades espaciais de análise do presente estudo. Apresenta a vulnerabilidade ambiental das Unidades Morfoestruturais, representadas pelo Cinturão Orogênico do Atlântico, Bacia Sedimentar do Paraná e Bacias Sedimentares Cenozóicas e Depressões Tectônicas; das Unidades Morfoesculturais, representadas pela Serra do Mar e Morros Isolados, os três Planaltos Paranaenses e Planícies e finalmente nas 50 Sub-Unidades Morfoesculturais contidas em cada uma das unidades anteriores.

Para cada unidade morfoescultural é apresentada suas características, os problemas esperados e sua aptidão de uso, baseando-se nos três classes de vulnerabilidade do meio físico obtidas do mapeamento: baixa, intermediária e alta. Os resultados oferecem subsidios para o planejamento e gestão ambiental do estado do Paraná.

MÉTODO O método adotado baseia-se no estudo da Análise Empírica da Fragilidade dos Ambientes Naturais e Antropizados propostos por Ross (1994), baseado em Tricart (1977), que sistematiza uma hierarquia nominal de fragilidade representada por valores ou pesos: muito fraca (peso: 1), fraca (peso: 2), média (peso: 3 ), forte (peso: 4) e muito forte (peso: 5).

As seqüências dos procedimentos operacionais executados no trabalho foram:

1) Organização das informações geomorfológicas, utilizando como unidade de análise as sub-unidades morfoesculturais definidas por Oka-Fiori et al. (2006) e Santos et al. (2006), aqui referidas como unidades geomorfológicas;

2) Adaptação do mapa de solos, escala 1:600.000, EMBRAPA (1981) para a nova classificação proposta pela
EMBRAPA (2006), considerando o primeiro nível categórico (ordem). Para a hierarquização das unidades de solos foram adaptadas as propostas de Ross (1994), Crepani et al. (2001) e Silveira et al. (2005), que consideram os horizontes diagnósticos de subsuperfície (Tab. 1) e a textura dos solos (Tab. 2). Nessa avaliação de atribuição dos pesos foram consideradas as vulnerabilidades aos processos de erosão, movimentos de massa, colapsos e contaminação dos solos.

3) Mapeamento da declividade obtido a partir de Modelo Digital de Elevação (MDE), dos dados SRTM (Shuttle Radar Topography Mission). Um MDE pode ser definido como uma representação espacial da superfície a partir de pontos que descrevem a topografia do terreno ou a elevação tridimensional de uma grade de dados a intervalos regulares ou irregulares (MONTGOMERY, 2003). Os intervalos de declividades adotados seguem a chave de classificação proposta por De Biasi (1977): $<5 \%, 5-12 \%, 12-30 \%, 30-47 \%$ e $>47 \%$ (Tab. 3), utilizados nos trabalhos de Oka-Fiori e Canali (2002) e Silveira et al. (2005);

4) O mapa de vulnerabilidade foi definido seguindo as matrizes abaixo apresentadas.

$\mathrm{Na}$ tabela 4 foram tabulados as unidades de solos com a textura, resultando em cinco agrupamentos (I, II, III, IV e V), que representam uma hierarquização crescente da vulnerabilidade

$\mathrm{Na}$ tabela 5 foram tabulados os agrupamentos anteriores (I, II, III, IV e V) com a declividade, originando três classes de vulnerabilidade geoambiental: baixa, que engloba as classes de muito fraca e fraca fragilidade; moderada, que corresponde a classe de média fragilidade e alta, que engloba forte e muito forte fragilidade, baseando-se em Ross (1992). A definição de três das classes de vulnerabilidade no presente estudo, visou diminuir a subjetividade na decisão de escolha das classes de muito baixa e baixa, muito alta e alta, além de melhor compatibilidade com a escala adotada.

5) Foram identificadas, no mapa geológico escala 1:600.000, MINEROPAR (2006), todas as unidades geológicas do estado do Paraná. Em especial, os corpos de metacalcáreos presentes no Primeiro Planalto $\mathrm{Pa}$ ranaense, incluídos no Grupo Açungui e na Formação Itaiacoca, classificados como de alta vulnerabilidade, em virtude de suas características específicas face aos processos esperados, como por exemplo, poluição das águas subterrâneas e facilidade de dissolução e conseqüentes processos de subsidência e recalques;

6) Identificação dos processos geoambientais predominantes em cada uma das cinqüenta unidades geomorfológicas que abrangem o estado do Paraná, a partir das relações pedológicas, geomorfológicas e geologia.

RESULTADOS A vulnerabilidade nas unidades geomorfológicas (Fig. 1) está condicionada aos seguintes processos: erosão, movimentos de massa, queda de blo- 
Tabela 1 - Hierarquização da vulnerabilidade por horizontes diagnósticos de subsuperficie.

\begin{tabular}{l|c|c}
\hline Unidades de solo & Hierarquia de vulnerabilidade & Peso \\
\hline Neossolo (litólico e quartzarênico) & Muito Alta & 5 \\
\hline Argissolo & Intermediária & 3 \\
\hline Cambissolos & Intermediária & 3 \\
\hline Espodossolo & Muito Alta & 5 \\
\hline Gleissolo & Muito Alta & 5 \\
\hline Latossolo & Muito Baixa & 1 \\
\hline Nitossolo & Baixa & 2 \\
\hline Organossolo & Muito Alta & 5 \\
\hline
\end{tabular}

Tabela 2 - Hierarquização da vulnerabilidade por textura.

\begin{tabular}{l|l|l}
\hline Textura dos solos & Hierarquia de vulnerabilidade & Peso \\
\hline Argilosa & Muito Baixa & 1 \\
\hline Argilosa / Média & Baixa & 2 \\
\hline Média e/ou Siltosa & Intermediária & 3 \\
\hline Arenosa / Média & Muito Alta & 5 \\
\hline Arenosa & Muito Alta & 5 \\
\hline
\end{tabular}

Tabela 3 - Hierarquização da vulnerabilidade por classe de declividade

\begin{tabular}{l|l|l}
\hline Classe de declividade & Hierarquia de vulnerabilidade & Peso \\
\hline Inferior a 5\% & Muito Baixa & 1 \\
\hline 5 a $12 \%$ & Baixa & 2 \\
\hline 12 a $30 \%$ & Intermediária & 3 \\
\hline 30 a $47 \%$ & Alta & 4 \\
\hline Superior a 47\% & Muito Alta & 5 \\
\hline
\end{tabular}

Tabela 4 - Matriz de tabulação entre as unidades de solo e textura

\begin{tabular}{l|c|c|c|c|c}
\hline Unidades de solo & Latossolo & Nitossolo & $\begin{array}{c}\text { Argissolo e } \\
\text { Cambissolo }\end{array}$ & $\begin{array}{c}\text { Gleissolo e } \\
\text { Alissolo }\end{array}$ & $\begin{array}{c}\text { Neossolo (litólico e quartzarênico), Espodossolo, } \\
\text { Organossolo, Solos de Mangue indiscriminados e } \\
\text { Afloramentos de rocha }\end{array}$ \\
\hline Argilosa & 11 & 12 & 13 & 14 & 15 \\
\hline Argilosa / Média & 21 & 22 & 23 & 24 & 25 \\
\hline Média e/ou Siltosa & 31 & 32 & 33 & 34 & 35 \\
\hline Arenosa / Média & 41 & 42 & 43 & 44 & 45 \\
\hline Arenosa & 51 & 52 & 53 & 54 & 55 \\
\hline
\end{tabular}

Agrupamento dos resultados obtidos da tabela 4: Agrupamento I - 11 / Agrupamento II - 12, 21 e 22 / Agrupamento III - 13, 23, 31, 32, 33 / Agrupamento IV - 14, 24, 34, 41, 42, 43 e 44 / Agrupamento V - 15, 25, 35, 45, 51, 52, 53, 54, e 55

cos, subsidência, recalques, colapsos de solo, inundações periódicas e contaminação de águas subterrâneas. O predomínio destes processos identificados em cada unidade mapeada fornece subsídios importantes para o planejamento regional, no entanto, não substituem estudos de maior detalhe que visem a utilização do solo para fins urbanos e rurais, tendo em vista a escala de menor detalhe adotada no trabalho. As características predominantes de cada unidade geomorfológicas são apresentadas no tabela $6(a, b, c)$.

No Paraná o Cinturão Orogênico do Atlântico é constituído por duas unidades morfoesculturais: Serra do Mar e Primeiro Planalto Paranaense.

Na unidade morfoescultural Serra do Mar predominam vulnerabilidades geoambientais associadas aos seguintes processos de evolução das paisagens:

- Alta vulnerabilidade a movimentos de massa e queda de blocos nas unidades geomorfológicas Morros Isolados Costeiros, Serra do Mar Paranaense e Blocos Soerguidos da Serra do Mar. Predominam Cambissolos e Neossolos Litólicos com textura argilosa, associados a relevo com alta declividade. Não são aptas a implan- 
Tabela 5 - Matriz de tabulação entre unidade de solo e declividade.

\begin{tabular}{l|c|c|c|c|c}
\hline \multicolumn{1}{c|}{ Agrupamentos } & \multirow{2}{*}{ I } & II & III & IV & V \\
\cline { 1 - 5 } Declividade & 11 & 12 & 13 & 14 & 15 \\
\hline Inferior a 6\% & 21 & 22 & 23 & 24 & 25 \\
\hline 6 a 12\% & 31 & 32 & 33 & 34 & 35 \\
\hline 12 a 30\% & 41 & 42 & 43 & 44 & 45 \\
\hline 30 a 47\% & 51 & 52 & 53 & 54 & 55 \\
\hline Superior a 47\% & & & & & \\
\hline
\end{tabular}

Classes de vulnerabilidade obtidas da Tabela 5: Vulnerabilidade I - 11, 12, 21 e 22 /

Vulnerabilidade II - 13, 23, 31, 32, 33

Vulnerabilidade III - 14, 15, 24, 25, 34, 35, 41, 42, 43, 44, 45, 51, 52, 53, 54, e 55

tação de infra-estrutura enterrada, vias de circulação e uso urbano. Devem ser verificadas as condições de declividade e de remoção dos solos, além de áreas com matacões aflorantes ou enterrados.

- Moderada vulnerabilidade a erosão laminar e linear na unidade geomorfológica Rampas de Pré-Serra e Serras isoladas, com predomínio de Argissolos textura argilosa, associados a relevo com baixa declividade. Há possibilidade de movimentos de massa localizados em áreas com altas declividades, onde predominam Cambissolos com textura argilosa. Sua ocupação deve estar sujeita a cuidados específicos. Nos cortes e aterros deve ser feita proteção vegetal.

$\mathrm{Na}$ unidade morfoescultural Primeiro Planalto Paranaense predominam vulnerabilidades geoambientais associadas aos seguintes processos:

- Alta vulnerabilidade a movimentos de massa e queda de blocos nas unidades geomorfológicas Blocos Soerguidos do Primeiro Planalto Paranaense, Planaltos Dissecados de Adrianópolis, Tunas do Paraná, Rio Branco do Sul e Alto Ribeira, com predomínio de Neossolos Litólicos associados a relevo com alta declividade. Secundariamente em Cambissolos textura argilosa associados a relevo com moderada declividade, ocorre moderada vulnerabilidade a processos erosivos. Tais áreas não são aptas a implantação de infra-estrutura enterrada, vias de circulação e uso urbano e rural. Apresenta potencial para desenvolvimento de atividades turísticas de baixo impacto. Secundariamente, exceto na primeira unidade, ocorre, associados às rochas carbonáticas, alta vulnerabilidade a subsidências, colapsos do solo e contaminação imediata do lençol freático e do aqüífero carste. As áreas com rochas carbonáticas são inadequadas para implantação de loteamentos residenciais, comerciais e industriais, disposição de resíduos de qualquer natureza e de lavouras que façam uso de agrotóxicos. Nas demais áreas a ocupação deve estar sujeita a cuidados específicos. Nos cortes e aterros deve ser feita proteção vegetal.

- Moderada vulnerabilidade a erosão laminar e linear nas unidades geomorfológicas Planalto do Complexo Gnáissico Migmatítico, Planalto do Alto Jaguariaíva e Planalto de Curitiba, predomínam Cambissolos, Argissolos e Latossolos textura argilosa, associados à relevo com baixa declividade. Secundariamente apresenta possibilidade de movimentos de massa nas áreas com alta declividade, onde a ocupação deve estar sujeita a cuidados específicos, principalmente nos cortes e aterros, que deve ser feita proteção vegetal. No Planalto de Curitiba as áreas com ocorrência da Formação Guabirotuba apresentam solos expansíveis suscetíveis a erosão, colapsos por compactação e instabilização em taludes. A ocupação deve estar sujeita a cuidados específicos.

- Baixa vulnerabilidade a erosão laminar e linear nas unidades geomorfológicas Planalto do Alto Iguaçu e Planalto de Castro, com predomínio de Latossolos textura argilosa, associados a relevo com baixa declividade. Secundariamente associados aos Gleissolos e Organossolos apresenta áreas sujeitas a inundações periódicas, material de baixa capacidade de suporte com possibilidades de recalques em fundações e edificações e contaminação do lençol freático. Nas áreas sobre a Formação Guabirotuba, Planalto do Alto Iguaçu, apresenta argilas expansíveis suscetíveis a erosão e colapsos por compactação. É recomendável para ocupação mediante práticas específicas.

No estado do Paraná, a Bacia Sedimentar do Paraná é constituída por duas unidades morfoesculturais: Segundo e Terceiro Planalto Paranaense.

Na unidade morfoescultural Segundo Planalto Paranaense predominam vulnerabilidades ambientais associadas aos seguintes processos de evolução das paisagens:

- Alta vulnerabilidade a movimentos de massa, queda de blocos e erosão nas unidades geomorfológicas Planaltos Resíduais da Formação Serra Geral, Planalto do Alto Ivaí, Planalto de Santo Antônio da Platina e Planalto de Ortigueira, com predomímio de Neossolos Litólicos textura argilosa, associados a relevo com moderada/alta declividade. Não são aptos a implantação de infra-estrutura enterrada, vias de circulação, uso urbano e rural. Devem ser verificadas as condições de declividade e de remoção dos solos, além de áreas com matacões aflorantes ou enterrados. Nos cortes e aterros deve ser feita proteção vegetal.

- Moderada vulnerabilidade a erosão nas unidades geomorfológicas Planalto de São Luiz do Purunã, 


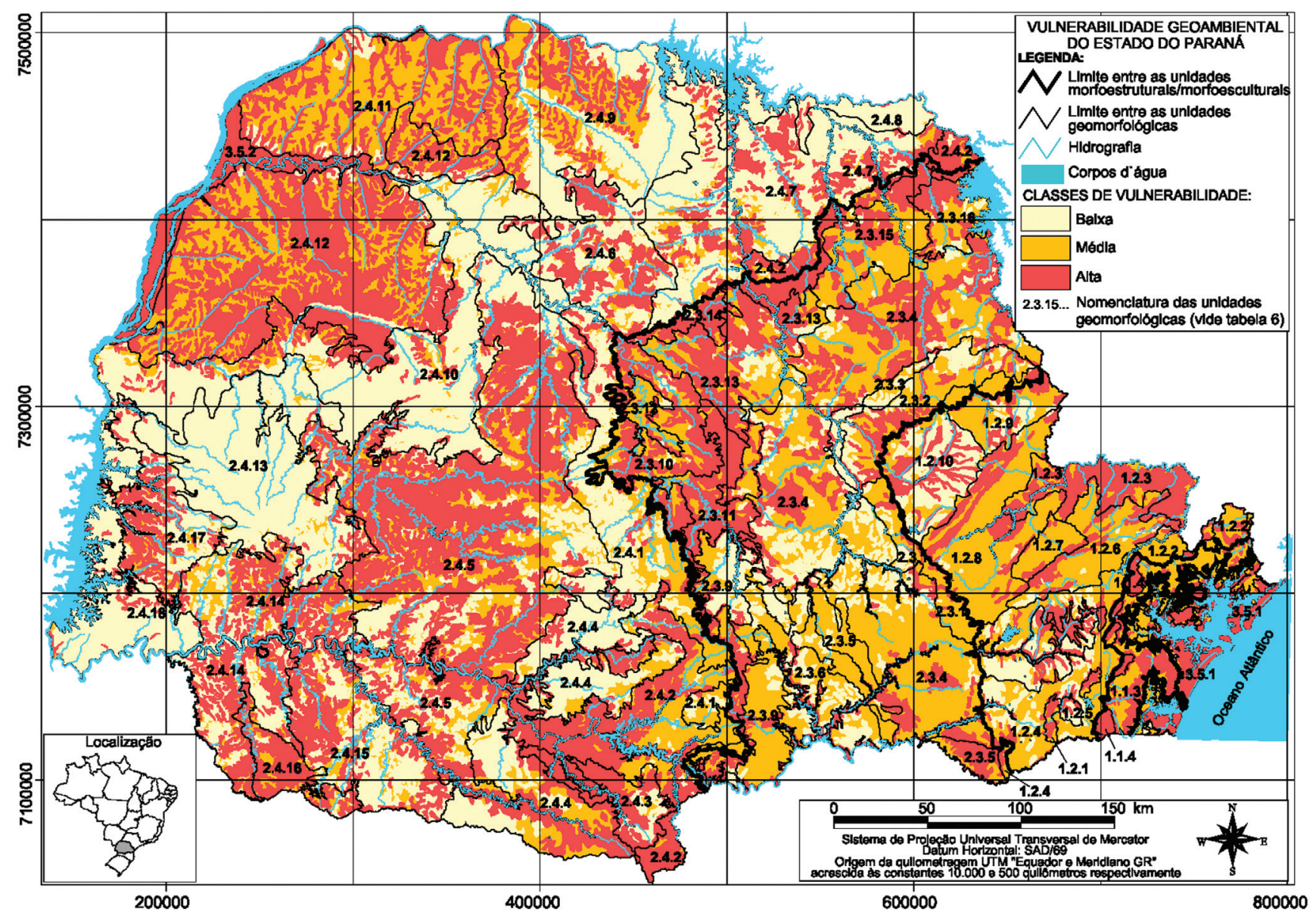

Figura 1 - Mapa da Vulnerabilidade Geoambiental do Estado do Paraná.

Planalto de Jaguariaíva e Planalto de São Mateus do Sul, com predomínio de Cambissolos e Latossolos de textura média/argilosa associados a relevos de baixa declividade. Os vales do Planalto de Jaguariaíva apresentam elevada dissecação vertical, aonde ocorrem Neossolos Litólicos associados a afloramentos rochosos com alta vulnerabilidade a queda de blocos, nessas áreas a ocupação deve estar sujeita a cuidados específicos. Apresenta potencial para desenvolvimento de atividades de turismo rural.

Esta classe de vulnerabilidade predomina, também, nas unidades Planalto de Ponta Grossa, Planalto de Guatá e Planalto de Prudentópolis, aonde ocorrem Cambissolos e Argissolos com textura argilosa, associados a relevo com baixa/moderada declividade. Apresentam secundariamente Neossolos e Argissolos textura média, associados a relevo com moderada declividade, com alta vulnerabilidade a erosão. Recomendável para ocupação com práticas específicas nas áreas com moderada vulnerabilidade. As demais áreas são indicadas para preservação e atividades de baixo impacto. Nos cortes e aterros deve ser feita proteção vegetal.

No Planalto de Irati, Planaltos Residuais da Formação Teresina, Planalto Cândido de Abreu, Planalto do Médio Cinzas e Planalto de Carlópolis, também com predomínio de moderada vulnerabilidade a erosão, ocorrem Argissolos textura argilosa e média/argilosa, associados a relevo com baixa declividade. Nos Planaltos Médio Cinzas e de Carlópolis encontra-se secundariamente Neossolos Litólicos textura média, associados a relevo com moderada declividade, alta vulnerabilidade a movimentos de massa e queda de blocos. Recomendável para ocupação com práticas específicas. Nos cortes e aterros deve ser feita proteção vegetal.

- Baixa vulnerabilidade a erosão na unidade geomorfológica Planalto de Tibagi, com predomínio de Latossolos textura argilosa, associados a relevo com baixa declividade. Recomendável para ocupação com práticas específicas.

$\mathrm{Na}$ unidade morfoescultural Terceiro Planalto Paranaense predominam vulnerabilidades ambientais associadas aos seguintes processos:

- alta vulnerabilidade a erosão, movimentos de massa e queda de blocos nas unidades geomorfológicas Planalto do Foz do Areia/Ribeirão Claro e Planalto de Clevelândia, com predomínio de Neossolos Litólicos textura argilosa, associados a relevo com moderada/ alta declividade. Não apto para implantação de infraestrutura enterrada, vias de circulação, uso urbano e rural. No Planalto de Clevelândia encontram-se, secundariamente, Nitossolos com textura argilosa, associados a relevo com baixa declividade, baixa vulnerabilidade a erosão. Nas áreas de alta vulnerabilidade não são aptos para implantação de infra-estrutura enterrada, vias de 
Tabela $6 a$ - Sintese dos resultados da Vulnerabilidade Geoambiental do Estado do Paraná. Unidade Morfoestrutural do Cinturão Orogênico do Atlântico.

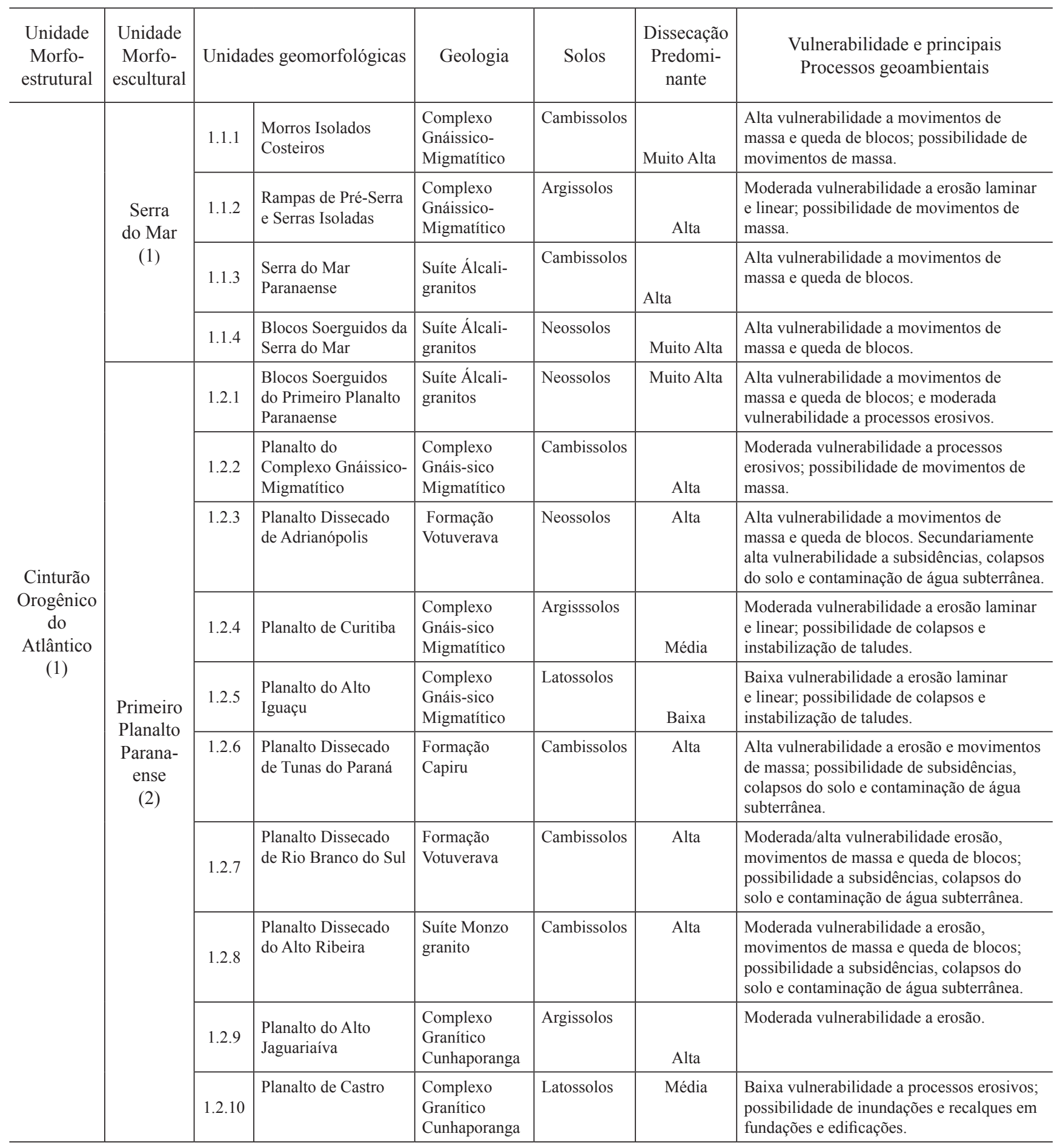

circulação, uso urbano e rural. Devem ser verificadas as condições de declividade e de remoção dos solos, além de áreas com matacões aflorantes ou enterrados. Nos cortes e aterros deve ser feita proteção vegetal. Nas áreas de baixa vulnerabilidade recomendável para ocupação com práticas específicas.

Esta classe de vulnerabilidade predomina, também, nas unidades Planalto do Alto/Médio Piquiri, Planalto de Francisco Beltrão, Planalto do São Francisco e Planalto do Alto Capanema, aonde ocorrem Neossolos
Litólicos textura argilosa, associados a relevo com moderada/alta declividade. Secundariamente Latossolos e Nitossolos textura argilosa, associados a relevo com baixa/moderada declividade, baixa vulnerabilidade a erosão. Recomendável para ocupação com práticas conservacionistas. Nos cortes e aterros deve ser feita proteção vegetal. Restrição de uso em áreas específicas com ocorrência de Neossolos Litólicos associados às altas declividades. Em áreas pontuais do Planalto do Alto Capanema, ocorrem Nitossolos textura argilosa, 
Tabela 6 - Sintese dos resultados da Vulnerabilidade Geoambiental do Estado do Paraná.(b) Unidade Morfoestrutural da Bacia Sedimentar do Paraná

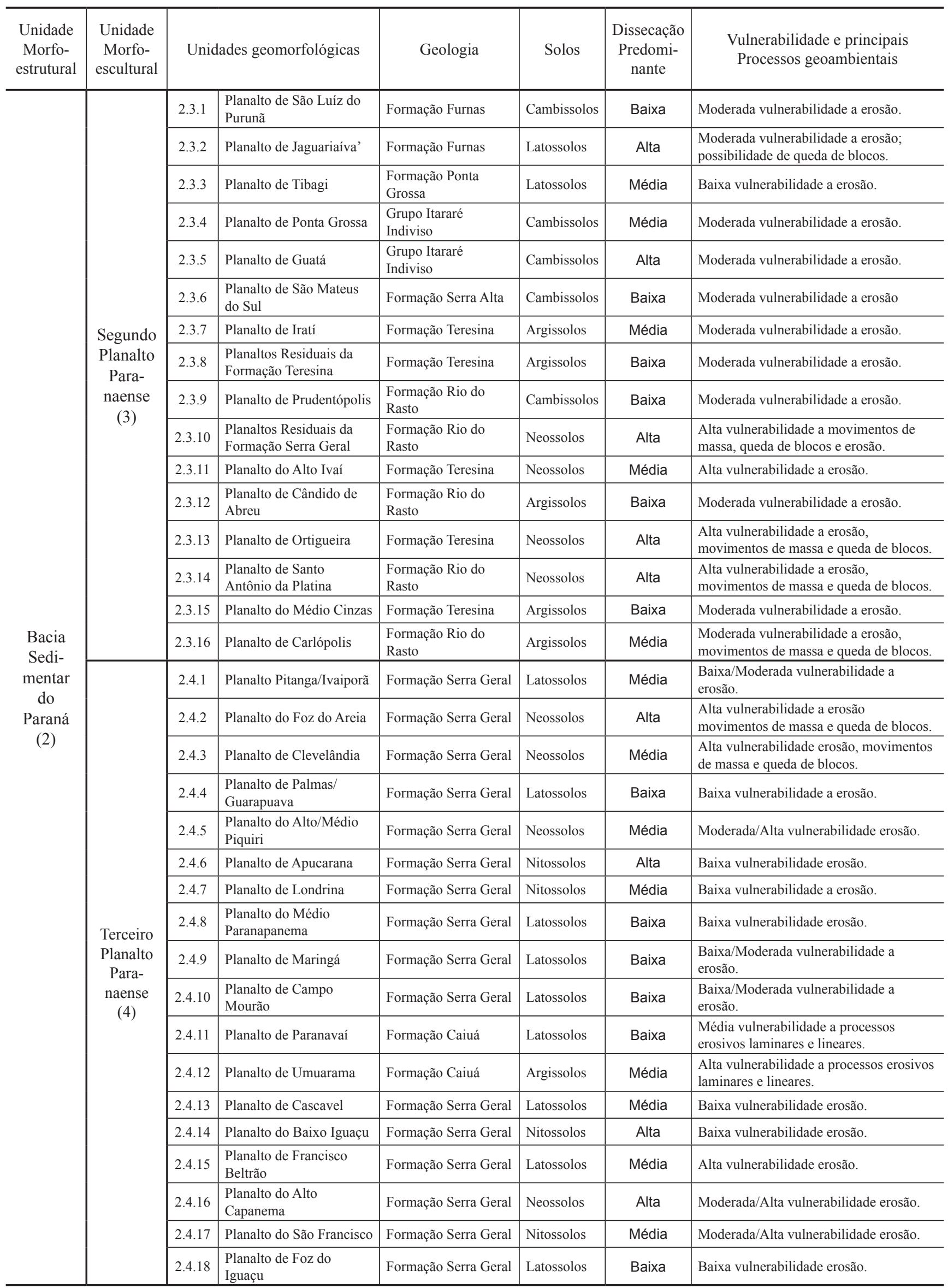


Tabela $6 c$ - Sintese dos resultados da Vulnerabilidade Geoambiental do Estado do Paraná.(b) Unidade Morfoestrutural das Bacias Sedimentares Cenozóicas e Depressões Tectônicas

\begin{tabular}{c|l|l|l|l|l|l|l}
\hline $\begin{array}{c}\text { Unidade } \\
\text { Morfoestrutural }\end{array}$ & $\begin{array}{c}\text { Unidade } \\
\text { Morfo- } \\
\text { escultural }\end{array}$ & \multicolumn{2}{|c|}{ Unidades geomorfológicas } & Geologia & Solos & $\begin{array}{c}\text { Dissecação } \\
\text { Predomi- } \\
\text { nante }\end{array}$ & $\begin{array}{c}\text { Vulnerabilidade e principais } \\
\text { Processos geoambientais }\end{array}$ \\
\hline $\begin{array}{c}\text { Bacias Sedimen- } \\
\text { tares Cenozóicas } \\
\text { e Depressões } \\
\begin{array}{c}\text { Tectônicas } \\
(3)\end{array}\end{array}$ & Planícies & 3.5 .1 & $\begin{array}{l}\text { Planícies (Litorânea } \\
\text { e Flúvio-Marinhas) }\end{array}$ & $\begin{array}{l}\text { Sedimentos } \\
\text { Recentes }\end{array}$ & Espodossolos & $\begin{array}{l}\text { Alta vulnerabilidade a erosão } \\
\text { marinho-fluvial e a poluição do } \\
\text { lençol freático. }\end{array}$ \\
\cline { 2 - 7 } & 3.5 .2 & Planícies Fluviais & $\begin{array}{l}\text { Sedimentos } \\
\text { Recentes }\end{array}$ & Organossolos & $\begin{array}{l}\text { Alta vulnerabilidade à poluição das } \\
\text { águas subterrâneas. }\end{array}$ \\
\hline
\end{tabular}

associados a relevo com moderada declividade e moderada vulnerabilidade a erosão.

$\mathrm{Na}$ unidade Planalto de Umuarama, também com predomínio de alta vulnerabilidade a erosão, ocorrem Argissolos textura arenosa/média, situados no terço médio/inferior das vertentes. Secundariamente Latossolos textura média, situados no terço superior das vertentes, apresentam moderada vulnerabilidade a processos erosivos laminares e lineares (ravinas e voçorocas). Recomendável para ocupação com práticas conservacionistas. Devem-se evitar tipos de uso do solo que ocasionem concentração de água superficial.

- Moderada vulnerabilidade a processos erosivos laminares e lineares (ravinas e voçorocas) na unidade geomorfológica Planalto de Paranavaí, com predomínio de Latossolos textura média, situados no terço superior/médio das vertentes. Secundariamente Argissolos textura arenosa/média, situados no terço inferior das vertentes, apresentam alta vulnerabilidade a processos erosivos laminares e lineares (ravinas e voçorocas). Recomendável para ocupação com práticas conservacionistas. Devem-se evitar tipos de uso do solo que ocasionem concentração de água superficial.

- Baixa vulnerabilidade a erosão laminar e linear nas unidades geomorfológicas Planalto Pitanga/Ivaiporã e Planalto de Palmas/Guarapuava, predominam Latossolos textura argilosa, associados a relevo com baixa/moderada declividade, Secundariamente Cambissolos e Neossolos Litólicos textura argilosa, associados a relevo com moderada declividade, apresentam moderada/alta vulnerabilidade a erosão. Recomendável para ocupação com práticas específicas. Adequados para uso rural e urbano em loteamentos residenciais, comerciais e industriais. Em áreas com Cambissolos e Neossolos Litólicos associados a relevo com moderada declividade o uso deve estar sujeito a práticas específicas, nos cortes e aterros deve ser feita proteção vegetal.

Esta classe de vulnerabilidade predomina, também, nas unidades Planalto de Apucarana e Planalto de Londrina, aonde ocorrem Nitossolos textura argilosa, associados a relevo com baixa declividade. Secundariamente Neossolos Litólicos textura argilosa, associados a relevo com moderada/alta declividade, apresentam alta vulnerabilidade a erosão. Recomendável para ocupação com práticas conservacionistas. Nos cortes e aterros deve ser feita proteção vegetal. Restrição de uso em áreas específicas com ocorrência de Neossolos Litólicos associados a alta declividade.

Nas unidades Planalto do Médio Paranapanema, Planalto de Cascavel, Planalto do Baixo Iguaçu, Planalto de Foz do Iguaçu, Planalto de Maringá e Planalto de Campo Mourão, também com predomínio de baixa vulnerabilidade a erosão laminar e linear, predominam Latossolos no terço superior das vertentes e Nitossolos no terço médio/inferior, com textura argilosa, associados a relevo com baixa declividade. Recomendável para ocupação com práticas conservacionistas. No Planalto de Maringá e Planalto de Campo Mourão, encontram-se secundariamente, nas rochas do Grupo Bauru, Argissolos textura arenosa/média, situados no terço médio/inferior das vertentes, alta vulnerabilidade a processos erosivos lineares (ravinas e voçorocas) e Latossolos textura média, no terço superior, moderada vulnerabilidade a erosão. Recomendável para ocupação com práticas conservacionistas. As áreas com baixa vulnerabilidade são adequadas para uso rural e urbano em loteamentos residenciais, comerciais e industriais. Nas áreas com média/alta vulnerabilidade, situadas nas rochas do Grupo Bauru, deve-se evitar tipos de uso do solo que ocasionem concentração de água superficial.

$\mathrm{Na}$ unidade morfoescultural Planícies predominam vulnerabilidades ambientais associadas aos seguintes processos de evolução da paisagem:

- alta vulnerabilidade a erosão marinha/fluvial e a poluição do lençol freático na unidade geomorfológica Planície Litorânea e Planícies Fluvio-Marinhas, com predomínio de Espodossolos textura arenosa e Gleissolos textura argilosa, associados a relevo com baixa declividade. São áreas suscetíveis a inundações periódicas, constituídas de material inconsolidado, de baixa capacidade de carga, com possibilidades de recalques/colapsos em fundações e edificações. A pouca profundidade do lençol freático coloca-as também como alta vulnerabilidade à poluição das águas subterrâneas. São inadequadas para implantação de loteamentos residenciais, comerciais e industriais, disposição de resíduos de qualquer natureza e de lavouras que façam uso de agrotóxicos.

- alta vulnerabilidade a inundações e a recalques/colapsos - na unidade geomorfológica de Planícies Fluviais, com prediomínio de Organossolos/Gleissolos e Neossolos Litólicos, associados a relevo com baixa declividade. A pouca profundidade do lençol freático 
coloca-as também como alta vulnerabilidade à poluição das águas subterrâneas. São inadequadas para implantação de loteamentos residenciais, comerciais e industriais, disposição de resíduos de qualquer natureza e de lavouras que façam uso de agrotóxicos.

CONCLUSÕES O mapeamento da vulnerabilidade geoambiental realizado com o emprego de técnicas de geoprocessamento levou a caracterização de três classes de vulnerabilidade, classificadas como baixa, moderada e alta no estado do Paraná, a partir das informações do meio físico (geologia, geomorfologia e pedologia).

Ao todo foram identificadas cinqüenta unidades geomorfológicas, úteis para embasar o planejamento da paisagem paranaense no âmbito regional em unidades homogêneas que permitem definir potencialidades e restrições de uso, bem como informações básicas para outras pesquisas ou ainda para fins didáticos.

$\mathrm{Na}$ Serra do Mar e Morros Isolados predominam processos de evolução da paisagem ligados principalmente a movimentos de massa e quedas de blocos.

No Primeiro Planalto Paranaense verificou-se o predomínio de processos ligados principalmente a movimentos de massa e quedas de blocos nas unidades de maior declividade e predomínio de solos rasos, enquanto processos de erosão laminar e linear predominam nas unidades com declividades moderadas/baixa e com solos mais espessos. Nas unidades de metacalcários e solos de caráter hidromórfico, predominam processos de subsidência e colapso de solos.

No Segundo Planalto Paranaense predominam os processos de evolução das vertentes da paisagem são devidos principalmente a movimentos de massa e queda de blocos nos Planaltos Residuais da Formação Serra Geral, associados a relevos de moderada/alta declividade e erosão laminar e linear associados a relevo de moderada declividade.

No Terceiro Planalto Paranaense, predominam queda de blocos e movimentos de massa associadas a rochas basálticos em relevo com alta declividade, enquanto nas rochas sedimentares da Formação Caiuá predominam processos de erosão laminar e linear, em relevo com baixa declividade e solos espessos.

$\mathrm{Na}$ Planície Litorânea e Flúvio-Marinhas os processos de evolução dizem respeito à erosão marinha/fluvial e poluição do lençol freático, enquanto que nas Planícies Fluviais são comuns as ocorrências de inundações e recalques/colapsos de solo.

Finalmente, espera-se que este mapeamento abra perspectivas para outras iniciativas semelhantes que, inclusive, contribuam para aperfeiçoá-lo, além de estimular estudos em escala de detalhe e de interações com as demais ciências ambientais.

Agradecimentos Aos revisores do trabalho e à MINEROPAR - Minerais do Paraná SA.

\section{Referências}

Crepani E., Medeiros J.S., Hernandez Filho P., Florenzano T.G., Duarte V., Barbosa C.C.F. 2001. Sensoriamento Remoto e Geoprocessamento Aplicados ao ZoneamentoEcológico-Econômico e ao Ordenamento Territorial. São José dos Campos, INPE, 100p.

De Biasi M. 1977. A carta clinográfica: os métodos de representação e sua confecção. Revista do Departamento de Geografia da USP, 06:45-61.

EMBRAPA Empresa Brasileira de Pesquisa Agropecuária. 2006. Sistema brasileiro de classificação de solo. Rio de Janeiro, Embrapa solos, 306p.

EMBRAPA Empresa Brasileira de Pesquisa Agropecuária. 1981. Levantamento de reconhecimento dos Solos do estado do Paraná. Curitiba, Convênio Governo do Estado do Paraná/IAPAR/EMBRAPA/SUDESUL, 1 mapa de solo, escala 1:600.000.

ESRI. 1996. Arcview Gis, versão 3.2. Spatial Analyst, versão 1.1. 3D Analyst, versão 1.0. Environmental Systems Research Institute.

MINEROPAR Minerais do Paraná. 2006. Mapa Geológico do Estado do Paraná. Curitiba, MINEROPAR, 1 mapa geológico, escala 1:650.000.

Montgomery D.R. 2003. Predicting landscape-scale erosion using digital elevation models. Comptes Rendus Geoscience, Paris, 335:1121-1130.

Oka-Fiori C. \& Canali N.E. 2002. Mapeamento Geomorfológico e Hidrográfico do Litoral Sul. In: Lima R.E. \& Negrelle R.R.B. (eds.) Meio Ambiente e Desenvolvimento do Litoral do Paraná - Subsídio à Ação. 1 ed., Curitiba, NIMAD-UFPR, p. 117-134.

Oka-Fiori C., Santos L.J.C., Canali N.E., Fiori A.P., Silveira C.T., Silva J.M.F., Ross J.L.S. 2006. Atlas Geomorfológico do Estado do Paraná: escala base 1:250.000, modelos reduzidos 1:500.000. Curitiba, MINEROPAR, 59p.

Pires Neto A. 1995. Planejamento territorial a abordagem geológico-geotécnica e o conceito de terreno ou abordagem de paisagem. Geografia, 08:51-62.

Ross J.L.S. 1994. Análise Empírica da Fragilidade dos Ambientes Naturais e Antropizados. Revista do Departamento de Geografia, São Paulo, 08:63-74.

Santos L.J.C., Oka-Fiori C., Canali N.E., Fiori A.P., Silveira C.T., Silva J.M.F., Ross J.L.S. 2006. Mapeamento Geomorfológico do Estado do Paraná. Revista Brasileira de Geomorfologia, 07:03-11.

Silveira C.T., Fiori A.P., Oka-Fiori C. 2005. Estudo das Unidades Ecodinâmicas de Instabilidade Potencial na APA de Guaratuba: subsídios para o planejamento ambiental. Bol. Paranaense de Geociências, 57:09-23.

Tricart J. 1977. Ecodinâmica. Rio de Janeiro, FIBGE/ SUPREN, 97p.

Manuscrito ID 8410

Submetido em 26 de julho de 2007 Aceito em 15 de dezembro de 2007 Sistema eletrônico de submissão 